http://ojs.stikes-muhammadiyahku.ac.id/index.php/herbapharma

\title{
FORMULASI SEDIAAN SERBUK EFFERVESCENT EKSTRAK BUAH MENGKUDU SEBAGAI ANTIHIPERTENSI
}

Hanna Fatarani Has ${ }^{1}$, Nur Azizah ${ }^{1,2 *}$, Juliani ${ }^{3}$

\footnotetext{
1,2,3 STIKes Muhammadiyah Kuningan

*E-mail : mom_zie80@yahoo.com
}

\begin{abstract}
ABSTRAK
Mengkudu (Morinda citrifolia L) merupakan salah satu tanaman obat yang berkhasiat untuk menurunkan tekanan darah. Mengkudu memiliki kandungan bahan aktif scopoletin yang dapat menurunkan resistensi perifer. Pengolahan mengkudu biasanya dalam bentuk tablet, kapsul, dan seduhan, dengan demikian perlu adanya bentuk yang lebih praktis yaitu dalam bentuk serbuk effervescent. Penelitian ini bertujuan untuk membuat serbuk effervescent dari ekstrak buah mengkudu. Metode penelitian ini adalah eksperimental laboratorium, dengan membuat berbagai jenis formulasi serbuk effervescent dari ekstrak buah mengkudu dengan variasi kandungan asam basa yaitu formula $A(2,5: 1,5: 1)$, formula $B(2: 1,5: 1,5)$, formula $C(3: 1: 1)$. Evaluasi sediaan yang dilakukan yaitu uji $\mathrm{pH}$, waktu alir, sudut diam, waktu dispersi, dan uji organoleptik. Hasil penelitian menunjukan bahwa formula II yang paling mendekati syarat serbuk effervescent yang baik dengan hasil uji organoleptik bau dan rasanya lemah, waktu larutnya 1,59 detik, dan $\mathrm{pH}$ nya 4. Kesimpulannya ekstrak buah mengkudu ini dapat dijadikan serbuk effervescent dengan rancangan formula tersebut, namun belum memenuhi standar karena tidak terdapat satu formulapun yang memenuhi semua standar uji evaluasi. Adapun variasi asam basa memiliki pengaruh pada formula yang dibuat sehingga pada hasil uji evaluasi beberapa diantaranya tidak memenuhi standar uji evaluasi yang telah ditentukan.
\end{abstract}

Kata Kunci: Mengkudu (Morinda citrifolia L.), Serbuk effervescent, Tekanan darah.

\begin{abstract}
Noni (Morinda citrifolia L.) is one of the medicinal plants that is efficacious for lowering blood pressure. Noni contains the active ingredient scopoletin which can reduce peripheral resistance. Noni processing is usually in the form of tablets, capsules, and steeping, thus it is necessary to have a more practical form, namely in the form of effervescent powder. This study aims to make effervescent powder from noni fruit extract. This research method is a laboratory experiment, by making various types of effervescent powder formulations from noni fruit extract with variations in acid-base content, namely formula $A(2,5: 1,5: 1)$, formula $B(2: 1,5: 1,5)$, the formula $C$ (3:1:1). Evaluation of the preparations carried out were $\mathrm{pH}$, flow time, angle of repose, dispersion time, and organoleptic tests. The results showed that formula II was closest to the requirements for a good effervescent powder with organoleptic test results of weak odor and taste, dissolution time of 1.59 seconds, and $\mathrm{pH}$ 4. not meet the standards because there is not a single formula that meets all the evaluation test standards. The acid-base variations have an influence on the formula that is made so that the results of the evaluation test some of them do not meet the predetermined evaluation test standards.
\end{abstract}

Keywords: Blood pressure, Effervescent powder,Noni (Morinda citrifolia L.) 


\section{PENDAHULUAN}

Prevalensi Hipertensi menurut data WHO (2011) menunjukkan di seluruh dunia, sekitar 972 juta orang atau 26,4\%. Menurut (Masriadi, 2016) Hipertensi di Asia tercatat 38,4 juta tahun 2000. Menurut data (Riskesda 2018) menyatakan prevalensi hipertensi di Indonesia sebesar 34,1\%. Estimasi jumlah kasus hipertensi di Indonesia sebesar 63.309 .620 orang. Dan menurut (Riskesdas 2013) Di Provinsi Jawa Barat, Prevalensi hipertensi yang didapat sebanyak $(29,4 \%)$.

Hipertensi merupakan penyakit berbahaya dan sering tidak menunjukkan keluhan khas selama belum ada komplikasi pada organ tubuh. Dalam mengontrol hipertensi dapat memanfaatkan pengobatan secara farmakologis dengan menggunakan obat-obatan sintetis ataupun dengan pengobatan alternatif seperti terapi herbal (Sari, 2015).

Mengkudu merupakan salah satu tanaman herbal alternatif yang digunakan sebagai penurun tekanan darah. Zat aktif yang dapat menurunkan tekanan darah didalam mengkudu yaitu scopoletin dan xeronin. Scopoletin bekerja dengan cara menurunkan tahanan atau resistensi perifer (Sari, 2015). Adapun kandungan lainnya menurut hasil penelitian Utami (2010), hasil uji fitokimia pada ekstrak buah mengkudu mengandung flavonoid, alkaloid, saponin. Senyawa flavonoid berperan sebagai antioksidan. Dan menurut (Rao dan Subramanian, 2009) Aktivitas tersebut diperkirakan salah satunya karena adanya aktivitas antioksidan dalam mengkudu dengan kandungan flavonoid dan senyawa fenolik yang dapat menurunkan tekanan darah.

Serbuk effervescent merupakan sediaan hasil dari gabungan senyawa asam dan basa yang bila ditambahkan dengan air ( $\mathrm{H} 2 \mathrm{O}$ ) akan bereaksi melepaskan karbon dioksida (CO2), yang biasanya terdiri dari natrium bikarbonat, asam sitrat dan asam tartrat. Keuntungan dari serbuk effervescent ini dapat menyamarkan rasa pahit dan bau yang tidak sedap serta lebih praktis sehingga dapat diberikan kepada orang yang mengalami kesulitan menelan tablet atau kapsul. (Ansel,1989).

Pengolahan buah mengkudu menjadi sediaan serbuk effervescent sebagai minuman sangat menguntungkan karena sediaannya yang praktis dan juga mudah dijangkau oleh masyarakat. Keberhasilan penelitian dalam memformulasikan sediaan serbuk effervescent ekstrak buah mengkudu diharapkan menjadi alternatif konsumsi produk yang baik serta dapat menjadi sumber penghasilan.

\section{BAHAN DAN METODE}

\section{Bahan dan Alat}

Ekstrak buah mengkudu (Morinda citrifolia L.) terstandar dari PT. Semarang Herbal Indoplant (No. Batch BT'0030220- MCL) asam sirtat(PT. DIPA Prasada husada), asam tartat(PT. DIPA Prasada husada), natrium bikarbonat(PT. DIPA Prasada husada), sukrosa(PT. DIPA Prasada husada), laktosa(PT. DIPA Prasada husada), aerosil (PT. DIPA Prasada husada), Mortar, stamper, cawan porselen, nampan, penganyak mesh 60, batang pengaduk (Herma), oven (Memmert), spatel, alumunium foil, sendok tanduk (kedai seneng), timbangan analitik (Shimadzu ATX224).

\section{Jenis Penelitian}

Jenis penelitian yang dilakukan adalah jenis penelitian eksperimental labolatorium dengan membuat sediaan formulasi serbuk effervescent ekstrak buah mengkudu (Morinda citrifolia L.) sebagai antihipertensi dengan perbandingan formula $A(2,5: 1,5: 1)$, formula $B(2: 1,5: 1,5)$, formula $C(3: 1: 1)$. Evaluasi yang dilakukan yaitu uji pH, waktu alir, sudut diam, waktu dispersi, dan uji organoleptik.

\section{Lokasi dan Waktu Penelitian}

Penelitian dilaksanakan pada bulan Mei tahun 2021 yang bertempat di Laboratorium Farmasi STIKes Muhammadiyah Kuningan. 


\section{Prosedur Penelitian}

\section{Ekstrak Buah Mengkudu}

Bahan yang digunakan adalah serbuk ekstrak terstandar buah mengkudu BT'0030220- MCL

2. Formulasi sediaan serbuk effervescent ekstrak buah mengkudu (Morinda citrifolia L.)

Tabel 1. Formula standar serbuk effervescent

\begin{tabular}{rlrrr}
\hline \multirow{2}{*}{ No. } & \multirow{2}{*}{ Formula bahan } & \multicolumn{3}{c}{ Formulasi bahan $(\mathrm{mg})$} \\
\cline { 3 - 5 } & & Fomula A & Formula B & Formula C \\
\hline 1 & Natrium bikarbonat & 600 & 750 & 1000 \\
2 & Asam sitrat & 1000 & 1000 & 750 \\
3 & Asam tartat & 600 & 450 & 450 \\
\hline
\end{tabular}

Sumber : (Rusita \& Rakhmayanti, 2019)

Tabel 2. Formula serbuk effervescent ekstrak buah mengkudu (Morinda citrifolia L.)

\begin{tabular}{llrrr}
\hline \multirow{2}{*}{ No } & \multirow{2}{*}{ Formula bahan } & \multicolumn{3}{c}{ Konsentrasi bahan $(\mathrm{mg})$} \\
\cline { 3 - 5 } & & \multicolumn{1}{c}{$\mathrm{F} 1$} & $\mathrm{~F} 2$ & \multicolumn{1}{c}{ F3 } \\
\hline 1 & Ekstrak Buah Mengkudu & 500 & 500 & 500 \\
2 & Sukrosa & 1500 & 1500 & 1500 \\
3 & Laktosa & 1000 & 1000 & 1000 \\
4 & Asam Sirtat & 750 & 600 & 900 \\
5 & Asam Tartat & 450 & 450 & 300 \\
6 & Natrium Bikarbonat & 300 & 450 & 300 \\
7 & Aerosil & 500 & 500 & 500 \\
& Total & 5000 & 5000 & 5000 \\
\hline
\end{tabular}

\section{Pembuatan serbuk effervescent ekstrak buah mengkudu (Morinda citrifolia L.)}

Pembuatan serbuk effervescent dengan metode kering, dalam metode ini satu molekul air yang ada pada setiap molekul asam sitrat bertindak sebagai unsur penentu bagi pencampuran serbuk. Asam sitrat dijadikan serbuk, kemudian dicampurkan dengan asam tartat, natrium bikarbonat, sukrosa, laktosa, aerosil dan yang terakhir zat aktifnya yaitu ekstrak buah megkudu (setelah disaring melewati ayakan 60 mesh) untuk meratanya pencampuran (Anam dkk., 2013). Setelah pengadukan serbuk diletakkan di atas nampan dan dioven pada suhu $33-40^{\circ} \mathrm{C}$, dibolak balik menggunakan spatel tahan asam atau bahan stainless. Bahan pangan berasam tinggi atau sedang bersifat sangat korosif terhadap baja, sehingga digunakan alat yang tahan asam. Pengovenan dilakukan dalam 3 menit kemudian serbuk dikeluarkan dari oven dan digerus melalui suatu ayakan(40 mesh) untuk membuat serbuk sesuai dengan yang diinginkan. Selanjutnya serbuk yang dihasilkan dikemas dalam kantung plastik klip dan ditutup secara cepat dan rapat (Novidiyanto \& Setyowati, 2008).

\section{Uji kualitas fisik}

Evaluasi dari ketiga formula dilakukan sesaat setelah sediaan di buat dengan pengujian kualitas fisik sediaan serbuk effervescent meliputi uji organoleptik, uji kecepatan alir, uji $\mathrm{PH}$, dan uji waktu dispersi. Dari hasil uji tersebut nantinya akan dipilih salah satu formula serbuk effervescent terbaik. Berikut adalah uji yang dilakukan pada sediaan serbuk effervescent ekstrak buah mengkudu (Morinda citrifolia L.).

\section{a) Uji Organoleptik}

Pengujian organoleptik menggunakan panca indra untuk mendeskripsikan bentuk,warna, rasa, dan bau serbuk.

b) Kecepatan Alir 
Serbuk dengan berat $100 \mathrm{~g}$ dimasukkan ke dalam corong yang ujung tangkainya ditutup. Penutup corong dibuka dan granul dibiarkan mengalir sampai habis. Serbuk mempunyai sifat alir yang baik bila waktu alirnya tidak lebih dari 10 detik.

c) Uji pH

Sejumlah sampel serbuk effervescent dilarutkan dalam air destilata menurut perbandingan tertentu, lalu dilakukan pengukuran $\mathrm{pH}$. Nilai $\mathrm{pH}$ dapat dibaca pada alat $\mathrm{pH}$ indikator.

d) Waktu Dispersi

Beberapa serbuk effervescent dilarutkan ke dalam beaker glass berisi air. Waktu larut dihitung dengan menggunakan stopwatch dimulai dari granul tercelup ke dalam aquadest sampai semua granul terlarut dan gelembung-gelembung di sekitar wadah mulai menghilang. Waktu larut granul effervescent berkisar antara 1-2 menit.

e) Sudut diam

Penetapan sudut diam granul dilakukan dengan memasukkan $100 \mathrm{~g}$ granul secara perlahanlahan melalui lubang bagian atas corong, sementara bagian bawah ditutup. Setelah semua serbuk dimasukkan, penutup dibuka dan serbuk dibiarkan keluar. Tinggi kerucut dan diameternya diukur sehingga dapat diketahui sudut diamnya. Sudut diam diperoleh dengan mengukur tinggi dan diameter tumpukan granul yang terbentuk dengan rumus:

$$
\tan \alpha=H / R
$$

Keterangan :

$\alpha=$ sudut istirahat/sudut diam

$\mathrm{H}=$ tinggi tumpukan

$\mathrm{R}=$ diameter tumpukan

\section{HASIL DAN PEMBAHASAN}

\section{Evaluasi Serbuk Effervescent Ekstrak Buah Mengkudu}

Evaluasi sifat fisik serbuk effervescent meliputi uji organolpetik, waktu alir, sudut diam, waktu dispersi, dan uji pH. Tujuan evaluasi adalah untuk mendapatkan serbuk yang baik.

a) Uji Organoleptik

Uji organoleptik ini termasuk uji fisik yang dilakukan dengan mengamati bentuk, bau, rasa, dan warnanya menggunakan panca indra. Hasil pengamatan uji organoleptik dapat dilihat pada Tabel 3.

Tabel 3. Uji Organoleptik Formulasi Serbuk Effervescent

\begin{tabular}{ccccc}
\hline Formula & Bentuk & Bau & Rasa & Warna \\
\hline \multirow{2}{*}{ I } & Serbuk hablur & Khas Aromatik & Asam & Coklat \\
& halus & sedang & kuat & muda \\
II & Serbuk hablur & Khas Aromatik & Asam & Coklat agak \\
& halus & lemah & lemah & tua \\
III & Serbuk hablur & Khas Aromatik & Asam & \\
& halus & kuat & sedang & Coklat tua \\
\hline
\end{tabular}

Didapatkan hasil pada formula I dengan bentuk serbuk hablur halus, bau khas aromatik sedang, rasa asam kuat, dan warna coklat muda. Pada Formula II dengan bentuk serbuk halus, bau khas aromatik lemah, rasa asam lemah, dan warna coklat agak tua. Dan pada formula III dengan bentuk serbuk hablur halus, khas aromatik kuat,rasa asam sedang, dan warna coklat tua. 


\section{b) Uji Waktu Alir}

Uji waktu alir dilakukan dengan cara mengalirkan serbuk effervescent ekstrak buah mengkudu melalui corong dan dihitung waktu alirnya menggunakan stopwatch. Hasil pengamatan waktu alir dapat dilihat pada Tabel 4.

Tabel 4. Uji Waktu Alir Formulasi Serbuk Effervescent

\begin{tabular}{cccc}
\hline \multirow{2}{*}{ Replikasi } & \multicolumn{3}{c}{ Waktu alir $100 \mathrm{~g}$ (detik) } \\
& Formula I & Formula II & Formula III \\
\hline 1 & 13,18 & 16,81 & 13,75 \\
2 & 15,39 & 13,49 & 10,92 \\
3 & 16,81 & 20,42 & 19,99 \\
\hline Rata-rata & 15,13 & 16,9 & 14,87 \\
\hline
\end{tabular}

Didapatkan hasil dengan 3 kali replikasi pada formula I yaitu 13.18, 16.81, dan 13.75 detik. Pada formula II yaitu 15.39, 13.49, dan 10.92 detik. Dan pada formula III yaitu 16.81 , 20.42, dan 19.99 detik. Sehingga dapat disimpulkan rata - rata pada formula I yaitu 15,13detik . Pada Formula II 16,9 detik . Dan pada formula III 14,87 detik.

\section{c) Uji Sudut Diam}

Uji sudut diam merupakan uji yang dilakukan dengan mengalirkan serbuk pada corong kemudian dihitung tinggi dan jari - jarinya menggunakan rumus yang sudah ditentukan. Hasil pengamatan uji sudut diam dapat dilihat pada Tabel 5.

Tabel 5. Uji Sudut Diam Formulasi Serbuk Effervescent

\begin{tabular}{|c|c|c|c|c|c|c|c|c|c|}
\hline \multirow{2}{*}{ Formula } & \multicolumn{3}{|c|}{$\mathrm{h}(\mathrm{cm})$} & \multicolumn{3}{|c|}{$\mathrm{r}(\mathrm{cm})$} & \multicolumn{2}{|c|}{ Rata-rata } & \multirow{2}{*}{$\begin{array}{l}\text { Sudut diam } \\
\qquad\left({ }^{\circ}\right)\end{array}$} \\
\hline & 1 & 2 & 3 & 1 & 2 & 3 & $\mathrm{H}$ & $\mathrm{R}$ & \\
\hline I & 4,5 & 4,5 & 4,2 & 7 & 7,5 & 6,25 & 4,4 & 6,9 & $32,49^{\circ}$ \\
\hline II & 4 & 5 & 4,5 & 6,25 & 6,5 & 6,75 & 4,5 & 6,5 & $34,68^{\circ}$ \\
\hline III & 4,5 & 4 & 4 & 6,25 & 6 & 6 & 4,2 & 6,1 & $34,52^{\circ}$ \\
\hline
\end{tabular}

\section{$\mathrm{h}$ : Tinggi $r$ : Jari-Jari}

Didapatkan hasil rata-rata tinggi dan jari-jari pada formula I dengan nilai 4,4 dan 6,9 . Pada Formula II dengan nilai 4,5 dan 6,5. Pada formula III dengan nilai 4,2 dan 6,1. Sehingga dapat disimpulkan nilai sudut diamnya yaitu pada formula I $\left(32,49^{\circ}\right)$, pada Formula II $\left(34,68^{\circ}\right)$, dan pada formula III $\left(34,52^{\circ}\right)$.

\section{d) Uji Waktu Dispersi}

Uji waktu dilakukan dengan cara memasukan serbuk kedalam beaker gelas yang diisi aquadest $100 \mathrm{ml}$. kemudian diamati waktu larutnya menggunakan stopwatch dimulai dari serbuk tercelup kedalam aquadest sampai semua serbuk terlarut dan gelembung gelembung disekitar beaker glass mulai menghilang. Hasil pengamatan uji waktu dispersi dapat dilihat pada Tabel 6 .

Tabel 6. Uji Waktu Dispersi Formulasi Serbuk Effervescent

Replikasi Waktu dispersi




\begin{tabular}{cccc}
\hline & $\begin{array}{c}\text { Formula } \\
\text { I }\end{array}$ & $\begin{array}{c}\text { Formula } \\
\text { II }\end{array}$ & $\begin{array}{c}\text { Formula } \\
\text { III }\end{array}$ \\
\hline 1 & 02,28 & 01,33 & 00,47 \\
2 & 03,01 & 02,25 & 01,53 \\
3 & 02,02 & 01,20 & 00,59 \\
\hline Rata-rata & 02,43 & 01,59 & 00,86 \\
\hline
\end{tabular}

Didapatkan hasil dengan 3 kali replikasi pada formula I yaitu 02.28, 01.33, dan 00.47 detik. Pada formula II yaitu 03.01, $\quad 02.25$, dan 01.53 detik. dan pada formula III yaitu $02.02,01.20,00.59$ detik. Sehingga dapat disimpulan nilai rata-rata pada formula I yaitu 02,43 detik. Pada Formula II 01,59 detik. Dan pada formula III 00,86 detik .

\section{e) Uji pH}

Uji pH dilakukan menggunakan $\mathrm{pH}$ indikator yang dimasukan kedalam beaker glass yang sudah terisi serbuk effervescent ekstrak buah mengkudu. Hasil pengamatan uji $\mathrm{pH}$ dapat dilihat pada Tabel 7 .

Tabel 7. Uji pH Formulasi Serbuk Effervescent

\begin{tabular}{cc}
\hline Formula & Nilai $\mathrm{pH}$ \\
\hline I & 2 \\
\hline II & 4 \\
\hline III & 3 \\
\hline
\end{tabular}

Didapatkan hasil pada formula I dengan nilai $\mathrm{pH}$ 2. Pada Formula II dengan nilai $\mathrm{pH}$ 4. Dan pada formula III dengan nilai $\mathrm{pH} 3$.

\section{PEMBAHASAN}

Pada Penelitian pembuatan formula sediaan serbuk effervescent ekstrak buah mengkudu dilakukan variasi pada masing-masing formula dengan cara membandingkan konsentrasi campuran asam sitrat, asam tartrat, dan natrium bikarbonat sesuai dengan penelitian yang dilakukan oleh Rushita \& Rakhmayanti (2019) .Perbandingan campuran asam dan basa dilakukan untuk memperoleh formula terbaik yang memenuhi syarat serbuk effervescent. Zat aktif utama dalam pembuatan formula serbuk effervescent adalah $500 \mathrm{mg}$ ekstrak buah mengkudu per satu sachet, 1 sachet serbuk berisi $5 \mathrm{~g}$.

Penambahan sukrosa sebanyak $1500 \mathrm{mg}$ dilakukan untuk memperbaiki rasa serbuk effervescent agar tidak terasa pahit karena mengkudu sendiri memiliki rasa yang pahit. Menurut Setiana dan Kusuma (2018), laktosa digunakan sebagai bahan pengisi, tujuan penggunaan laktosa adalah meningkatkan jumlah total padatan, memperbesar volume, mempercepat proses pengeringan dan mencegah kerusakan bahan akibat panas. Menurut (Departemen Kesehatan, 1995) Aerosil dapat digunakan sebagai bahan pengering. Aerosil mampu menyerap air sampai $40 \%$ berat, tanpa kehilangan sifatnya sebagai serbuk yang mampu mengalir bebas dan memiliki sifat lekat, sifat aliran dan sifat sebarnya sangat baik, daya serapnya terhadap air dan minyak besar.

Pengamatan pengujian organoleptik pada masing-masing formula serbuk effervescent dengan menggunakan panca indera untuk mendeskripsikan tekstur, warna, bau, dan rasa (Departemen Kesehatan RI, 2000). Dari hasil uji organoleptik didapatkan hasil pada formula I dengan bentuk serbuk hablur halus, bau khas aromatik sedang, rasa asam kuat, dan warna coklat muda. Pada Formula II dengan bentuk serbuk halus, bau khas aromatik lemah, rasa asam lemah, dan 
warna coklat agak tua.Pada formula III dengan bentuk serbuk hablur halus, khas aromatik kuat,rasa asam sedang, dan warna coklat tua.

Dari ketiga formula serbuk effervescent ekstrak buah mengkudu memiliki kecepatan alir yang kurang baik dan tidak memenuhi syarat karena $\leq 10$ detik. Hal ini disebabkan effervescent yang dibuat memiliki kandungan lembab yang besar, gaya gesek antar partikel akan meningkat seiring besarnya kandungan lembab. Menurut (Astuti \& Wijaya, 2016) Gaya gesek antar partikel yang lebih kuat yang menyebabkan turunnya mobilitas serbuk untuk mengalir, dengan demikian kecepatan alir akan semakin rendah. Selain itu pada proses pembuatan serbuk effervescent sangat sulit sekali menjaga suhu dan kelembaban udara sehingga kualitas granul yang dihasilkan menjadi lembab. Dikarenakan faktor inilah kecepatan alir granul penelitian ini menjadi menurun.

Dari pengukuran sudut diam pada ketiga formula serbuk effervescent tersebut tidak memenuhi syarat. Menurut Aulton (2002), syarat sudut diam yang sangat baik adalah $\leq 25^{\circ}$. Hal ini diakibatkan oleh kandungan lembab yang besar sehingga menyebabkan gaya kohesif yang besar pula. Menurut (Astuti \& Wijaya, 2016) Suatu granul yang tidak kohesif akan mengalir baik, menyebar membentuk timbunan yang rendah sehingga membentuk sudut yang lebih kecil. Dan besar kecilnya sudut diam yang dihasilkan dapat dipengaruhi oleh banyaknya serbuk, ukuran serbuk, dan diameter corong.

Dari uji waktu larut pada formula serbuk effervescent Pada formula II dan III telah memenuhi syarat sedangkan pada formula ke I tidak memenuhi syarat. Karena nilai dari formula I yaitu 02,43 detik sehingga waktunya $\leq 2$ menit. Sesuai penelitian yang dilakukan oleh Purwandari (2007), waktu larut atau dispersi serbuk eff ervescent yang baik adalah $\leq 2$ menit. Verawati (2006) menyatakan bahwa waktu larut yang rendah disebabkan natrium bikarbonat habis bereaksi menghasilkan gelembung-gelembung $\mathrm{CO} 2$ yang dapat melarutkan komponen komponen effervescent. Menurut Lewis (1987) kelarutan serbuk dipengaruhi oleh komposisi, kondisi proses selama pengeringan, suhu pelarut dan metode pencampuran.

Dari pengukuran $\mathrm{pH}$ pada formula serbuk effervescent menunjukan formula II memenuhi syarat $\mathrm{pH}$ serbuk effervescent yaitu 4 . Sedangkan pada formula I dan III tidak memenuhi syarat karena memiliki tingkat keasaman $\mathrm{pH}$ yang tinggi yaitu 2 dan 3 . Sesuai dengan penelitian Novidiyanto (2008) banyaknya konsentrasi asam yang digunakan akan menghasilkan serbuk effervescent dengan tingkat keasaman yang tinggi. Hal tersebut kemungkinan karena dalam penelitian ini menggunakan 2 sumber asam memiliki tingkat keasaman yang kuat, sehingga terjadi kelebihan mol asam yang tidak bereaksi dengan sejumlah basa yang tersedia (Sari, 2019). Menurut Departemen IImu dan Teknologi Pangan IPB (2010), nilai pH serbuk effervescent yang dihasilkan berkisar 2,81-3,52 artinya produk yang dihasilkan termasuk produk pangan yang berasam tinggi. Dalam penelitian Kusnadhi (2003), bahwa terbentuknya $\mathrm{CO}_{2}$ pada saat reaksi effervescent dalam air yang sebagian akan larut membentuk asam karbonat akan mengurangi ion $\mathrm{H}+$ dalam larutan sehingga menyebabkan keasaman pada larutan dan berakibat nilai $\mathrm{pH}$ akan rendah.

\section{SIMPULAN}

Berdasarkan hasil uji dari formula sediaan serbuk effervescent ekstrak buah mengkudu (Morinda citrifolia L.) sebagai antihipertensi dapat disimpulkan bahwa ekstrak buah mengkudu ini tidak dapat dijadikan serbuk effervescent dengan rancangan formula tersebut. Karena tidak terdapat satu formulapun yang memenuhi semua standar uji evaluasi. Adapun variasi asam basa memiliki pengaruh pada formula yang dibuat sehingga pada hasil uji evaluasi beberapa diantaranya tidak memenuhi standar uji evaluasi yang telah ditentukan. 


\section{REFERENSI}

Anam, dkk., 2013. Kajian karakteristik fisik dan sensoris serta aktivitas antioksidan dari granul effervescent buah beet (beta vulgaris) dengan perbedaan metode granulasi dan kombinasi sumber asam. Universitas Sebelas Maret, Surakarta.

Ansel, H. 1989, Pengantar Bentuk Sediaan Farmasi, edisi IV, UI Press, Jakarta

Departemen Kesehatan. (1995), Farmakope Indonesia, Edisi IV, Departemen Kesehatan Republik Indonesia, Jakarta. 448, 515, 771, 1000.

Ditjen POM. (2000). Parameter Standar Umum Ekstrak Tumbuhan Obat. DepKes RI, Jakarta. Halaman 3-5, 13-17, 30-31.

Kemenkes Ri. 2013. Riset Kesehatan Dasar; RISKESDAS. Jakarta: Balitbang Kemenkes Ri.

Kemenkes RI. 2018. Riset Kesehatan Dasar: Riskesdas 2018. Jakarta: Kementerian Kesehatan RI.

Kusnadhi, F.F. 2003. Formulasi Produk Minuman Instan Lingzhi-Jahe Effervescent. Skripsi. Fakultas Teknologi pertanian. IPB. Bogor.

Masriadi. (2016). Epidemiologi Penyakit Tidak Menular. Jakarta: Trans Info Media.

Novidiyanto dan Setyowati. (2008). Formulasi serbuk effervescent sari wortel. Jurnal Agritech, 28(4): 150-157.

Purwandari, L.E., 2007. Optimasi Campuran Asam Sitrat-Asam Tartrat Dan Natrium Bikarbonat Sebagai Eksipien Dalam Pembuatan Granul Effervescent Ekstrak Rimpang Temulawak (Curcuma xanthorriza Roxb.) Secara Granulasi Basah Dengan Metode Desain Faktorial. Universitas Sanata Dharma: Fakultas Farmasi.

Rao, U.S.M. and Subramanian, S. 2009. Biochemical Evaluation of Antihyperglycemic and Antioxidative Effects of Morinda citrifolia Fruit Extract Studied in Streptozotocin-Induced Diabetic Rats. Medicinal Chemistry Research, 18: 433-446.

Rusita, Y. D., \& Rakhmayanti, R. D. (2019). Formulasi Sediaan Serbuk Effervescent Ekstrak Daun Kelor (Moringa oleifera L.) (Vol. 2). http://prosiding.unimus.ac.id

Sari, C. Y. (2015). Penggunaan Buah Mengkudu (Morinda ciftrifoliaL.) untuk Menurunkan Tekanan Darah Tinggi. J Majority, 4(3), 34-40.

Sariyani , M.D., Ariyanti ,K.S., \& Utami, L.N. (2019). Metode Terapi Non Farmakologi Berbasis Kearifan Lokal Yang Diharapkan Oleh Lansia Untuk Mengontrol Tekanan Darah Di Batubulan, Gianyar, Bali. Jurnal Kesehatan Terpadu 3(1) : 1 - 3.

Verawati (2006). Optimasi Rasio Asam sitrat dan $\mathrm{NaHCO} 3$ terhadap Disintegration Time Tablet Effervescent The Hijau serta Prediksi umur Simpannya, Tesis, Sekolah Pasca Sarjana. Universitas Gadjah Mada, Yogyakarta.

WHO. 2011. Hypertension fact sheet. Departement of sustainable Development and Healthy Environments. 